\title{
Eksplorasi Software $R$ untuk Fitting Semivariogram Spherical Menggunakan Pemrograman Linear dan Uji Analisis Sensitivitas
}

\author{
Tegar Bratasena WKM1), Diah Chaerani'), Budi Nurani R ${ }^{1)}$ \\ Departemen Matematika, Fakultas MIPA, Universitas Padjadjaran \\ Jl. Raya Bandung Sumedang KM 21 Jatinangor, Sumedang 45363 \\ Email:tegar.bratasena@gmail.com,d.chaerani@unpad.ac.id,budi.nurani@unpad.ac.id
}

\begin{abstract}
Abstrak
Semivariogram adalah diagram setengah variansi dari observasi spasial yang berada pada suatu jarak tertentu. Model ini digunakan untuk mendeskripsikan kolerasi spasial. Pada Model Semivariogram terdapat dua parameter yaitu sill dan range. Semivariogram terdiri dari semivariogram eksperimental dan semivariogram teoritis. Dalam makalah ini dikaji Eksplorasi Software $R$ untuk Fitting Semivariogram Spherical menggunakan Pemrograman Linear dan Uji Analisis Sensitivitas. Hasil optimal diperoleh dari meminimumkan Nilai Error Semivariogram Eksperimental terhadap Semivariogram Spherical. Setelah mendapatkan hasil error yang optimal lalu dilakukan uji Analisis Sensitivitas. Untuk studi kasus, Model Semivariogram diterapkan pada data penyebaran abu vulkanik dari Gunung Tambora dan dihitung dengan menggunakan bantuan software $R$. Hasil eksperimen numerik menunjukkan bahwa estimator yang optimal dapat diperoleh dengan menyelesaikan permasalahan Pemrograman Linear yang dibangun. Kata kunci: Analisis Sensitivitas, Pemrograman Linear, Semivariogram
\end{abstract}

\begin{abstract}
Semivariogram is a half of variance of spatial observations in a certain distance. This model is used to describe the spatial correlation. Semivariogram model contain two parameters, i,e., sill and range. Semivariogram consists of semivariogram experimental and theoretical semivariogram. In this paper, an Exploration of Software $R$ for fitting Spherical Semivariogram using Linear Programming and Sensitivity Analysis is studied. The optimal result is obtained by minimizing the error value between experimental semivariogram and theoretical semivariogram. After getting the optimal result, the Sensitivity Analysis is done. For a case study, semivariogram models are applied to the data of volcanic ash that spreads from Mount Tambora and the calculation is done using Software R. The result of numerical experiments show that the optimal estimator can be obtained by solving the problem of Linear Programming.
\end{abstract}

Keywords: Linear Programming, Semivariogram, Sensitivity Analysis

\section{Pendahuluan}

Geostatistika adalah aplikasi ilmu statistika yang digunakan dalam ilmu kebumian dan pertambangan. Geostatistika berhubungan dengan Data Spasial. Dalam Geostatistika terdapat metode yang digunakan untuk melakukan estimasi cadangan mineral. Metode tersebut dikenal dengan Metode Kriging, menurut (Cressie, 1993) kriging adalah suatu teknik perhitungan untuk estimasi suatu variabel teregional yang menggunakan pendekatan bahwa data yang dianalisis dianggap sebagai suatu realisasi dari suatu variabel acak dan keseluruhan variabel acak tersebut membentuk suatu fungsi struktural dengan menggunakan model struktural variogram. Dalam beberapa tahun terakhir Semivariogram banyak digunakan untuk menyelesaikan masalah, antara lain, pada salah satu jurnal yang ditulis oleh ( $\mathrm{Li}, 2010)$ berjudul Automatic Fit of Variogram yang membahas fitting Semivariogram Eksperimental menggunakan Pemrograman Linear. Pada jurnal ini, dibahas tentang menyelesaikan permasalahan fitting Semivariogram Eksperimental menggunakan Pemrograman Linear. Berikutnya, permasalahan Semivariogram juga dibahas oleh (Solana-Gutierrez \& Merino-deMiguel, 2011) dengan judul A Variogram Model Comparison for Predicting Forest Change. Pada 
jurnal ini dibahas Model Variogram yang digunakan untuk memprediksi perubahan hutan. Tidak hanya itu model Semivariogram juga dibahas dalam jurnal The Dynamic of Spatial Extent of Land Use in the Fringe of Jakarta Metropolitan: A Semivariogram Analysis yang ditulis oleh (Fitriani \& Sumarminingsih, 2014). Pada jurnal yang ditulis oleh Rao (2009) dengan judul Penaksiran Parameter Semivariogram dengan Metode Linear Programming yang melakukan penaksiran parameter semivariogram menggunakan pemrograman linear. Merujuk kepada jurnal yang berjudul Semivariogram Fitting with Pemrograman Linear oleh (Chen \& Jiao, 2001), masalah Semivariogram dapat diselesaikan menggunakan metode Pemrograman Linear.

Semivariogram merupakan fungsi yang menyatakan kolerasi spasial pada data spasial. Dalam Geostatistika, Semivariogram digunakan untuk mencari parameter yang menentukan bobot pada kriging. Sebelum menggunakan Metode kriging, parameter Semivariogram ditaksir terlebih dahulu. Terdapat beberapa model Semivariogram teoritis, diantaranya Spherical Model, Exponential Model, Gaussian Model, Power Model, Linear Model, dan DeWisjan Model.

Salah satu metode yang dapat digunakan untuk menaksir parameter pada model semivariogram adalah dengan menggunakan metode Pemrograman Linear. Pengerjaan dengan menggunakan metode Pemrograman Linear yang bertujuan untuk mendapatkan hasil optimal dari setiap model semivariogram. Penyelesaian model Semivariogram menggunakan metode Pemrograman Linear lebih mudah jika menggunakan bantuan software aplikasi. Pada penelitian ini, digunakan Software $R$ sebagai alat bantu hitung pada Model Semivariogram yang diselesaikan dengan metode Pemrograman Linear.

\subsection{Data Spasial}

\section{Metode Penelitian}

Data spasial adalah data yang diperoleh dari hasil pengukuran suatu lokasi. Data spasial merupakan data dependen karena berasal dari lokasi spasial yang berbeda yang mengindikasikan ketergantungan antara nilai pengukuran dengan lokasi (Cressie, 1993). Dinyatakan bahwa $\{Z(s): \mathrm{s} \in D\}$ adalah proses spasial untuk $D$ bersifat tertentu dan $D \subset R^{2}$, ruang Euclides dimensi dua dan $s$ adalah posisi dari lokasi.

\subsection{Asumsi Stasioner Orde Dua}

Himpunan variabel random $\{Z(s): \mathrm{s} \in D\}$ memenuhi asusmi stasioner orde dua jika memenuhi syarat-syarat sebagai berikut:

$$
E[Z(s)]=\mu(s)=\mu, \forall s \in D
$$

Persamaan di atas menunjukkan ekspektasi atau mean dari variabel random konstan untuk setiap lokasi padas ${ }^{s}$.

$$
E\{[Z(s)-E(Z(s))][Z(s+h)-E(Z(s+h))]\}=\operatorname{cov}[Z(s), Z(s+h)]=C(h)
$$

dengan:

1. Lokasi dinyatakan dalam bentuk koordinat, $s=\left\{(x, y) \mid x, y \in{ }^{\circ}\right\}$.

2. Lokasi yang berjarak $h$ dari lokasi $s$ dengan $h=(\Delta x, \Delta y)$ sehingga untuk $s+h$ dapat ditulis $s+h=\left\{(x+\Delta x, y+\Delta y) \mid x, y \in^{\circ}\right\}$.

3. $Z(s)$ : nilai pada lokasi $s$.

4. $Z(s+h)$ : nilai pada lokasi $s+h$.

\subsection{Variogram dan Semivariogram}

Variogram adalah suatu perangkat dasar untuk visualisasi pemodelan dan eksplorasi auto spasial dari variabel teregional, sedangkan semivariogram adalah setengah dari variogram dengan $\operatorname{simbol} \gamma(h)$. Jadi variogram menentukan ukuran dari variansi yang digunakan untuk menentukan jarak dimana nilai-nilai data pengamatan menjadi tidak ada kolerasinya. 


\section{Variogram dan Semivariogram Eksperimental}

Variogram adalah suatu perangkat dasar untuk visualisasi pemodelan dan eksplorasi auto spasial dari variabel teregional, sedangkan semivariogram adalah setengah dari variogram dengan $\operatorname{simbol} \gamma(h)$.

Jadi variogram menentukan ukuran dari variansi yang digunakan untuk menentukan jarak dimana nilai-nilai data pengamatan menjadi tidak ada kolerasinya.

\section{Semivariogram Teoritis}

Variogram eksperimental adalah variogram yang diperoleh dari data yang diamati. Variogram didefinisikan sebagai berikut:

$$
2 \hat{\gamma}(h)=\operatorname{var}[Z(s)-Z(s+h)]
$$

dengan mengasumsikan data memenuhi stasioner orde dua maka persamaan (3) dapat ditulis sebagai berikut:

$$
2 \hat{\gamma}=E[Z(s)-Z(s+h)]^{2}
$$

Karena Semivariogram merupakan setengah dari Variogram, maka dari persamaan (4) dapat ditulis:

$$
\hat{\gamma}(h)=\frac{1}{2 N(h)} \sum_{i=1}^{N(h)}\left[Z\left(s_{i}\right)-Z\left(s_{i}+h\right)\right]^{2}
$$

dengan $\hat{\gamma}(h)$ adalah nilai semivariogram eksperimental dengan jarak $h, Z\left(s_{i}\right)$ nilai pengamatan di titik $s_{i}, Z\left(s_{i}+h\right)$ nilai pengamatan di titik $s_{i}+h, N(h)$ banyaknya pasangan titik yang berjarak $h$. Sifat-sifat Semivariogram adalah sebagai berikut :

1. Untuk suatu data yang berjarak nol atau $h=(0,0)$ maka nilainya sama dengan nol.

2. Nilai semivariogram selalu nonnegative.

$$
\gamma(0)=0
$$

3. Semivariogram adalah fungsi genap.

$$
\gamma(h) \geq 0
$$

$$
\gamma(-h)=\gamma(h)
$$

\subsection{Optimisasi: Pemrograman Linear dan Analisis Sensitivitas}

Optimisasi adalah usaha untuk mendapatkan hasil yang terbaik dari suatu keadaan yang didapat (Rao, 2009). Tujuannya adalah untuk meminimumkan usaha yang dibutuhkan atau untuk mendapatkan hasil yang maksimal dari keuntungan yang didapat. Karena usaha yang dibutuhkan atau keuntungan yang didapat dalam suatu kondisi, dapat dinyatakan dalam suatu fungsi dari beberapa variabel penentu, optimisasi bisa didefinisikan menjadi proses mencari nilai maksimum atau nilai minimum dari suatu kondisi.

Dalam makalah ini, penyelesaian masalah diselesaikan dengan menggunakan Pemrograman Linear, dimana Pemrograman Linear adalah metode optimisasi untuk mencari solusi dari suatu permasalahan dengan fungsi objektif dan fungsi kendala yang muncul dalam bentuk fungsi linear dari variabel keputusan (Rao, 2009). Persamaan dari kendala dalam masalah pemrograman linear bisa dalam bentuk persamaan ataupun pertidaksamaan. Pemrograman linear yang menyelesaikan masalah optimisasi pertama kali dikenal pada tahun 1930 dalam ekonomi pada saat menghasilkan metode untuk mencari nilai yang optimal dari persediaan. Pada perang dunia ke II, George B. Dantzig memformulasikan masalah pemrograman linear yang umum dan merancang solusi metode simpleks pada tahun 1947. Pada umumnya, pemrograman linear memuat perencanaan dari aktivitas untuk menghasilkan suatu solusi yang optimal.

Menurut (Rao, 2009) karekteristik dari Pemrograman Linear yang dinyatakan dalam bentuk standar adalah fungsi objektif dengan tipe meminimumkan suatu fungsi, semua kendala yang terlibat adalah suatu persamaan, dan semua variabel keputusan yang terlibat bersifat nonnegative.

Setelah didapat hasil yang optimal dari suatu permasalahan Pemrograman Linear, dilakukan gangguan atau perubahan pada konstanta $b_{i}$ menjadi $b_{i}+\Delta b_{i}$ sehingga permasalahan baru berbeda dengan dari asal untuk ruas sebelah kanan. Setelah itu, dilakukan pemeriksaan efek perubahan $b_{i}$ menjadi $b_{i}+\Delta b_{i}$ dari optimal awal. Dari yang diketahui basis optimal jika hubungan nilai koefisien sesuai ke nonbasis variabel $\bar{c}_{j}$ bernilai nonnegative. Mengingat prosedur menurut dimana $\bar{c}_{j}$ didapatkan, nilai dari $\bar{c}_{j}$ tidak berhubungan dengan $b_{i}$. Nilai dari $\overline{c_{j}}$ tergantung hanya kepada basis, dari koefisien dari batasan matriks, dan koefisien awal adalah fungsi objektif. dimana: 


$$
\bar{c}_{j}=c_{j}-\pi^{T} A_{j}=c_{j}-c_{B}^{T} B^{-1} A_{j}
$$

Perubahan di $b_{i}$ akan mempengaruhi nilai dari variabel basis dalam solusi optimal dan iotimalnya variabel basis tidak terpengaruhi dari perubahan $b_{i}$. Demikian juga jika solusi basic yang baru tetap feasible untuk sisi sebelah kanan, yaitu

$$
X_{B}^{\prime}=B^{-1}(b+\Delta b) \geq 0
$$

maka optimal basis awal, $B$ tetap optimal untuk permasalahan baru, dengan solusi awal adalah $X_{B}=\left(\begin{array}{c}x_{1} \\ x_{2} \\ \mathrm{M} \\ x_{m}\end{array}\right)$ diberikan oleh,

$$
X_{B}=B^{-1} b
$$

maka persamaan (15) dapat ditulis

$$
x_{i}^{\prime}=x_{i}+\sum_{j=1}^{m} \beta_{i j} \Delta b_{j} \geq 0, \quad i=1,2, \mathrm{~K}, m
$$

dimana

$$
B^{-1}=\left[\beta_{i j}\right]
$$

Maka optimal basis awal $B$ tetap optimal dihasilkan dari perubahan pada $b_{i}, \Delta b_{i}$, memenuhi persamaan (16). perubahan dalam variabel ke $i$ optimal variabel basis, $\Delta x_{i}$, berdasarkan perubahan $b_{i}$ diperoleh

$$
X_{B}^{\prime}-X_{B}=\Delta X_{B}=B^{-1} \Delta b
$$

yaitu

$$
\Delta x_{i}=\sum_{j=1}^{m} \beta_{i j} \Delta b_{j}, \quad i=1,2, \mathrm{~K}, m
$$

Kesimpulannya, perubahan pada nilai optimal dari fungsi objektif $(\Delta f)$ berdasarkan perubahan $\Delta b_{i}$ bisa didapatkan

$$
\Delta f=c_{B}^{T} \Delta X_{B}=c_{B}^{T} B^{-1} \Delta b=\pi^{T} \Delta b=\sum_{j=1}^{m} \pi_{j} \Delta b_{j}
$$

\section{Hasil dan Pembahasan}

\subsection{Transformasi Garis Lintang dan Garis Bujur Ke Bentuk Universal Transverse Mercator} (UTM)

Data penyebaran abu yang diperoleh dari PVMBG berbentuk Peta Isopach yang disajikan pada gambar berikut:

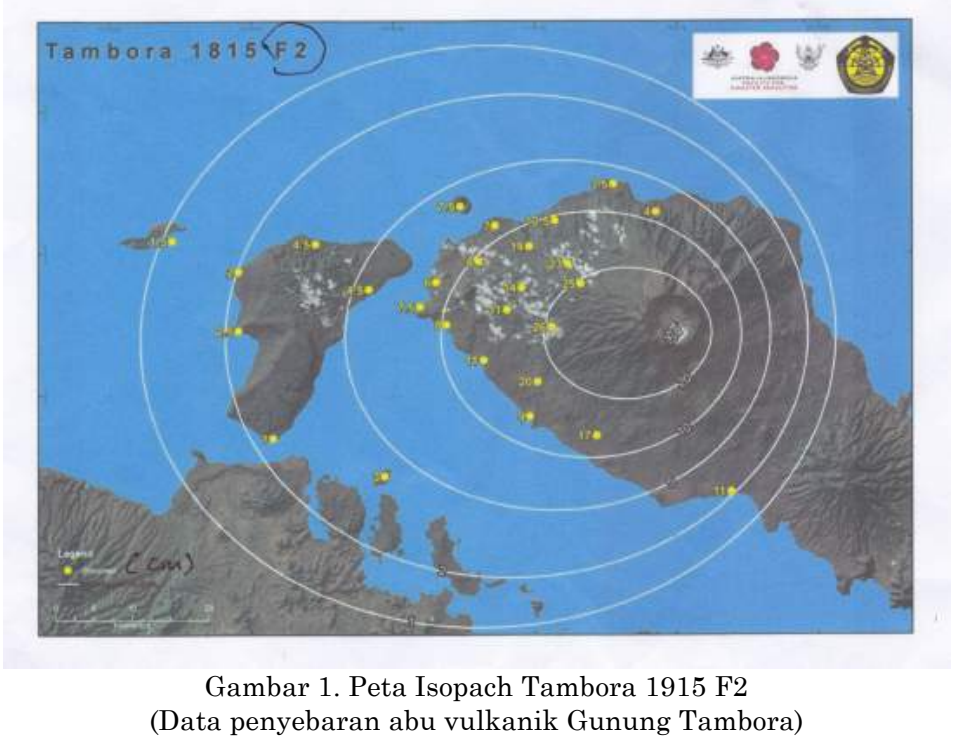

Titik pada gambar merupakan hasil sampel ketebalan abu dalam sentimeter yang diamati, dari titik tersebut dilakukan plotting dengan bantuan aplikasi software Google Earth untuk mendapatkan koordinat garis bujur dan garis lintang. Setelah itu, dilakukan konversi kedalam bentuk UTM. 


\subsection{Model Semivariogram Spherical dengan Metode Pemrograman Linear}

Karena fungsi kendala bertanda "=" maka merujuk ke Metode Simpleks memenuhi situasi infeasible. Maka fungsi kendala diformulasi ulang dengan Metode Simpleks Dua Fase. Diketahui pada subbab sebelumnya model pemrograman linear adalah sebagai berikut:

$$
\begin{aligned}
& \min g(z)=\left(\begin{array}{l}
u \\
\theta
\end{array}\right)^{T}\left(\begin{array}{l}
t \\
b
\end{array}\right)=\sum_{i=1}^{m} t_{i} \\
& \text { s.t }\left(\begin{array}{cccc}
I & X & -I & 0 \\
0 & 2 X & -I & I
\end{array}\right)\left(\begin{array}{l}
t \\
b \\
\alpha \\
\gamma
\end{array}\right)=\left(\begin{array}{c}
y \\
2 y
\end{array}\right) \\
& \left(\begin{array}{l}
t \\
b
\end{array}\right) \geq \theta
\end{aligned}
$$

Setelah nilai $h$ dan $\gamma(h)$ di subtitusi ke $X$ dan $y$ maka fungsi kenadala pada persamaan (4.1) dapat ditulis:

$$
\begin{aligned}
\text { s.t } t+553 b_{1}+6553810 b_{2}-\alpha & =63 \\
1107 b_{1}+13107621 b_{2}-\alpha+\gamma & =126 \\
t, b_{1}, b_{2} & \geq 0
\end{aligned}
$$

Setelah itu ditambahkan slack variabel berupa $y_{1}$ dan $y_{2}$ menjadi:

$$
\begin{aligned}
t+553 b_{1}+6553810 b_{2}-\alpha+y_{1} & =63 \\
1107 b_{1}+13107621 b_{2}-\alpha+\gamma+y_{2} & =126 \\
t \quad-f & =0
\end{aligned}
$$

Dengan mendefinisikan $w$ sebagai:

$$
w=y_{1}+y_{2}
$$

Atau semua persamaan dapat ditulis menjadi satu:

$$
\begin{aligned}
t+553 b_{1}+6553810 b_{2}-\alpha+y_{1} & =63 \\
1107 b_{1}+13107621 b_{2}-\alpha+\gamma+y_{2} & =126 \\
t \quad f & =0 \\
y_{1}+y_{2}-w & =0
\end{aligned}
$$

Lalu dilakukan pengurangan $w$ terhadap penjumlahan fungsi kendala:

$$
-t-1660 b_{1}-19661431 b_{2}+2 \alpha-\gamma-w=-189
$$

Setelah itu dilakukan iterasi menggunakan tabel simpleks sehingga didapat solusi optimal dicapai ketika nilai $t=4.8063 \cdot 10^{-6}$ dan $b_{2}=9.6127 \cdot 10^{-6}$ karena $f=t$ maka solusi optimalnya adalah $4.8063 \cdot 10^{-6}$

\subsection{Penerapan Software $R$}

Setelah dilakukan konversi data ke dalam bentuk UTM, selanjutnya data di input ke dalam Software $R$ agar mendapatkan nilai semivariogram eksperimental. Dengan bantuan Microsoft Excel untuk mencari nilai $h$. Setelah didapatkan nilai $h$ dan $h^{3}$ maka diketahui nilai $x_{1}$ dan $x_{2}$ adalah 553 dan 6553810 . Dalam penelitian ini, subtitusikan data sehingga dapat diperoleh sebuah Persamaan Linear sebegai berikut:

$$
\begin{array}{ll} 
& \min t \\
\text { s.t } t & t+553 \cdot b_{1}+6553810 . b_{2}-\alpha-\gamma=63 \\
& 1107 \cdot b_{1}+13107621 \cdot b_{2}-\alpha+\gamma=126 \\
& b_{1}, b_{2}, t \geq 0
\end{array}
$$

Dengan menggunakan Software $R$ didapatkan nilai $b_{1}=0, b_{2}=9.612728 \cdot 10^{-6}$, dan $t=4.806364 \cdot 10^{-6}$.

\subsection{Uji Analisis Sensitivitas}

Setelah mendapatkan hasil yang optimal, maka dilakukan uji analisis sensitivitas untuk menguji apakah model sensitive terhadap perubahan variabel. Untuk masalah ini variabel yang akan diganggu adalah variabel di sebelah kanan yaitu $b_{i}$. Dari hasil optimal pada tabel simpleks di subab sebelumnya didapatkan hasil yang optimal. Maka dapat diketahui: 


$$
\begin{aligned}
X_{B} & =\left(\begin{array}{l}
x_{1} \\
x_{3}
\end{array}\right)=\left(\begin{array}{l}
4.806364 \cdot 10^{-6} \\
9.612728 \cdot 10^{-6}
\end{array}\right) \\
c_{B} & =\left(\begin{array}{l}
c_{1} \\
c_{3}
\end{array}\right)=\left(\begin{array}{l}
1 \\
0
\end{array}\right) \\
B & =\left(\begin{array}{ll}
1 & 6553810 \\
0 & 13107621
\end{array}\right) \\
B^{-1} & =\left(\begin{array}{ll}
\beta_{11} & \beta_{13} \\
\beta_{31} & \beta_{33}
\end{array}\right)=\left(\begin{array}{cc}
1 & -4.99999961854253 \cdot 10^{-1} \\
0 & 7.62914948486838 \cdot 10^{-8}
\end{array}\right) \\
\Delta b & =\left(\begin{array}{l}
10 \\
20
\end{array}\right)
\end{aligned}
$$

Untuk menguji model, variabel $b_{i}$ diganggu dengan rentang penambahan 10, jadi dari rentang $73,83,93, \ldots, 163$.

Maka untuk solusi optimal yang baru untuk perubahan $y_{1}=73$ adalah $X_{B}^{\prime}$ dengan cara melakukan perhitungan:

$$
\begin{gathered}
X_{B}^{\prime}=\left(\begin{array}{c}
t^{\prime} \\
b_{2}^{\prime}
\end{array}\right)=X_{B}+\Delta X_{B}=X_{B}+B^{-1} \Delta b \\
X_{B}+B^{-1} \Delta b=\left(\begin{array}{c}
0.000005568364174 \\
0.00001113855825
\end{array}\right)
\end{gathered}
$$

maka solusi optimalnya adalah

$$
f_{\min }^{\prime}=f_{\min }+\Delta f=f_{\min }+c_{B}^{T} \Delta X_{B}
$$

$$
\begin{aligned}
& f_{\min }+c_{B}^{T} \Delta X_{B}=-4.806364 \cdot 10^{-6}+ \\
&\left(\begin{array}{ll}
1 & 0
\end{array}\right)\left(\begin{array}{c}
7.62 \cdot 10^{-7} \\
0.000001525829899
\end{array}\right) \\
&=-4.04436 \cdot 10^{-6}
\end{aligned}
$$

Maka solusi optimal yang baru adalah $4.04436 \cdot 10^{-6}$. Untuk menghitung $y_{2}=83, y_{3}=93, y_{4}=103, \ldots, y_{10}=$ 163 dilakukan dengan cara yang sama seperti menghitung $y_{1}$. Selanjutnya hasil $f^{\prime}$ di plot kedalam bentuk grafik, seperti dapat dilihat pada Gambar 2.

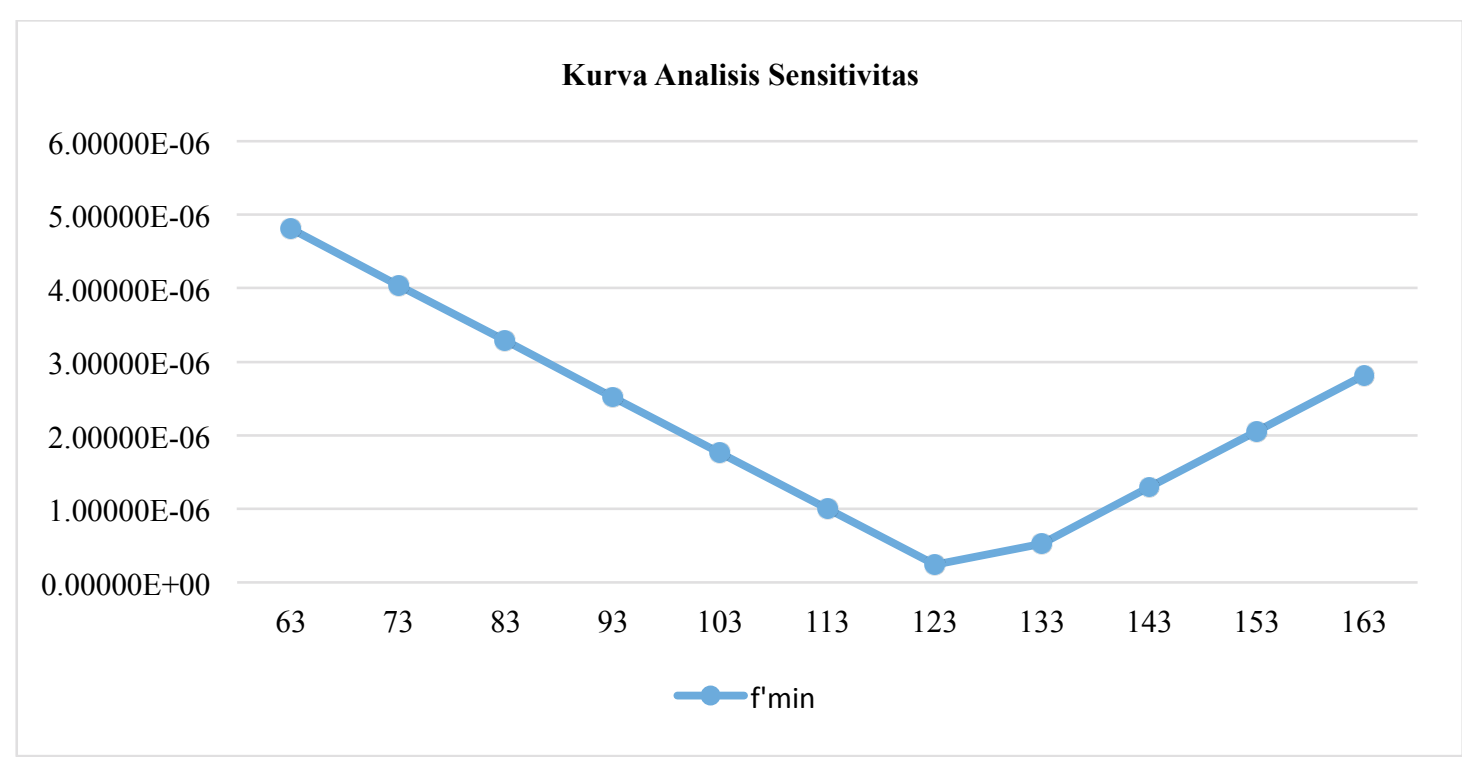

Gambar 2. Kurva Analisis Sensitivitas

\section{Kesimpulan}

Dalam penerapan metode Pemrograman Linear untuk menaksir Semivariogram model Spherical, bentuk standar model Spherical diubah terlebih dahulu menjadi bentuk persamaan linear. Setelah itu, dibuat fungsi tujuan dan fungsi kendala dari model Semivariogram Spherical. 
Penerapan software $R$ dibantu dengan metode CPLEX dalam koding penulisan masalah pemrograman linear. Data yang sudah di plot dari sumber dianalisis dengan Microsoft Excel untuk mencari nilai $h$. Setelah itu penyelesaian pemrograman linear diselesaikan di dalam software $R$ untuk mendapatkan nilai $t$ minimum atau nilai selisih antara semivariogram eksperimental dan semivariogram teoritis atau bisa disebut nilai error.

Untuk uji analisis sensitivitas dilakukan iterasi dari model pemrograman linear kedalam tabel simpleks. Setelah mengubah variabel pada ruas sebelah kanan maka dapat dicari hasil optimalnya. Variabel yang diubah dalam suatu rentang menghasilkan beberapa hasil optimal yang baru, lalu hasil optimal yang baru di plotting ke dalam grafik garis. Dari grafik garis dapat dilihat bahwa solusi optimal tidak stabil terhadap perubahan variable $b_{i}$.

\section{Ucapan Terima Kasih}

Penulis mengucapkan terima kasih kepada Rektor Universitas Padjadjaran yang telah mendanai penelitian dan publikasi paper melalui Academic Leadership Grant 2016.

\section{Daftar Pustaka}

1. Cressie, N. (1993). Statistics For Spatial Data, Revised Edition.

2. Chen, Y., \& Jiao, X. (2001). Computers \& Geosciences. Semivariogram fitting with linear programming , 71-76.

3. Fitriani, R., \& Sumarminingsih, E. (2014). The Dynamic of Spatial Extent of Land Use in the Fringe of Jakarta Metropolitan: A Semivariogram Analysis. 5th International Confrence on Environmental Science and Development - ICESD 2014 , 198-202.

4. Li, S. (2010). Automatic Fit of the Variogram. Third International Conference on Information and Computing, Volume 4, 129 - 132.

5. Rao, S. S. (2009). Engineering Optimization Theory and Practice, Third Edition. New Jersey: Wiley Eastern Limited.

6. Solana-Gutierrez, J., \& Merino-de-Miguel, S. (2011). A Variogram Model Comparison for Predicting Forest Change. Spatial Statistics 2011: Mapping Global Change, Volume 7, 383-388.

7. Sallan, J. M., Lordan, O., \& Fernandez, V. (2015). Modeling and Solving Linear Programming with $R$. OmniaScience.

8. Wardani, Y. P. (2010). Penaksiran Parameter Semivariogram dengan Metode Linear Programming. 
Tegar Bratasena WKM, Diah Chaerani, Budi Nurani R / JMI Vol. 12 No. 2, Oktober 2016 pp. 75-82 